\title{
Modeling the Effects of Mortality on Sea Otter Populations
}

Scientific Investigations Report 2010-5096 



\section{Modeling the Effects of Mortality on Sea Otter Populations}

By James L. Bodkin and Brenda E. Ballachey

Scientific Investigations Report 2010-5096 


\title{
U.S. Department of the Interior \\ KEN SALAZAR, Secretary
}

\section{U.S. Geological Survey \\ Marcia K. McNutt, Director}

\section{U.S. Geological Survey, Reston, Virginia: 2010}

\author{
For more information on the USGS — the Federal source for science about the Earth, its natural and living resources, \\ natural hazards, and the environment, visit http://www.usgs.gov or call 1-888-ASK-USGS \\ For an overview of USGS information products, including maps, imagery, and publications, \\ visit http://www.usgs.gov/pubprod \\ To order this and other USGS information products, visit http://store.usgs.gov
}

Any use of trade, product, or firm names is for descriptive purposes only and does not imply endorsement by the U.S. Government.

Although this report is in the public domain, permission must be secured from the individual copyright owners to reproduce any copyrighted materials contained within this report.

Suggested citation:

Bodkin, J.L., and Ballachey, B.E., 2010, Modeling the effects of mortality on sea otter populations: U.S. Geological Survey Scientific Investigations Report 2010-5096, 12 p. 


\section{Contents}

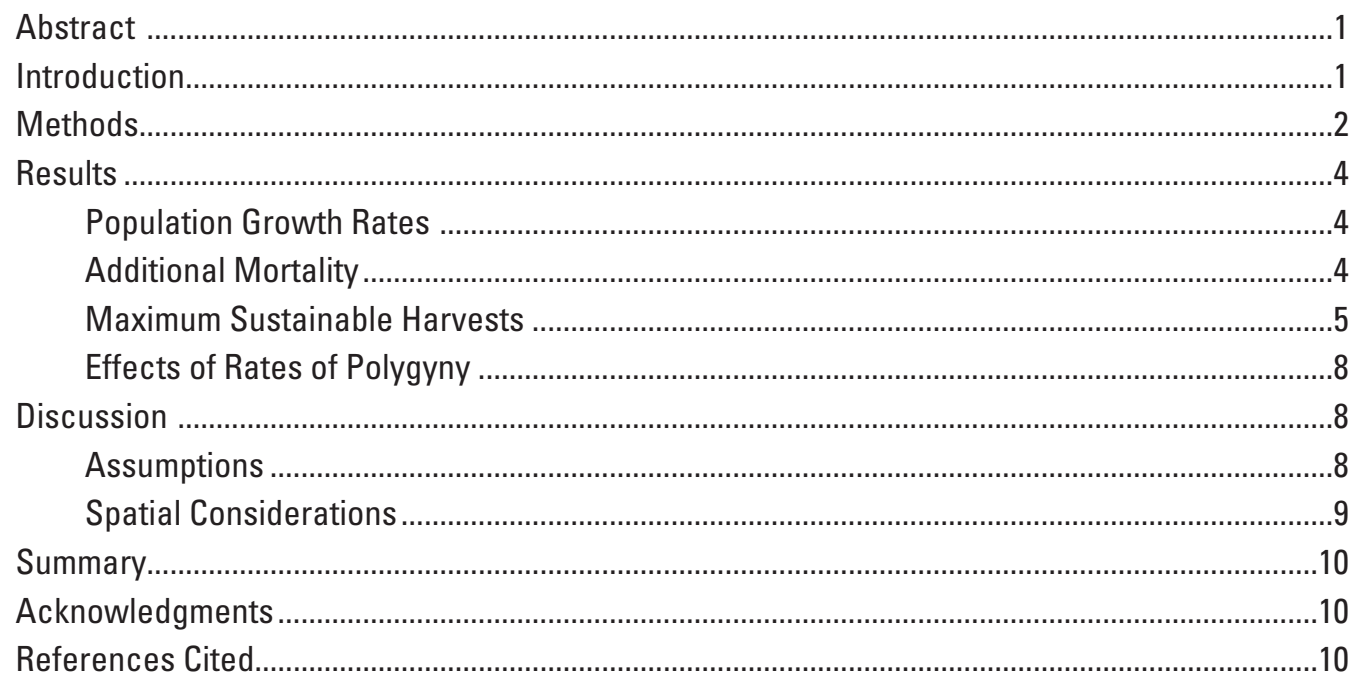

\section{Figures}

Figure 1. Graph showing population trajectories over 20 years for sea otter populations exhibiting stable, moderate, and rapid rates of change using empirical estimates of age and sex specific reproduction and survival ..... 5

Figure 2. Graphs showing effects of additional sex and age specific mortality (removals) on rates of change in sea otter populations that are stable, increasing moderately, and increasing rapidly

Figure 3. Graphs showing maximum annual sustainable rates of harvest for sea otter populations experiencing stable, moderate, and rapid growth, and maximum sustainable average annual harvest number for male only, and male to female ratios of $3: 1$ and $1: 1$.

\section{Tables}

Table 1. Vital rates of sea otters used to generate population models representing stable $(\lambda=1.005)$, moderate $(\lambda=1.072)$, and rapid $(\lambda=1.145)$ rates of change 


\section{Conversion Factors and Acronyms}

Conversion Factors

\begin{tabular}{clc}
\hline Multiply & By & To obtain \\
\hline square kilometer $\left(\mathrm{km}^{2}\right)$ & 0.3861 & square mile $\left(\mathrm{mi}^{2}\right)$ \\
\hline
\end{tabular}

Acronyms

USGS United States Geological Survey

USFWS United States Fish and Wildlife Service

MMM Marine Mammals Management

MMPA Marine Mammals Protection Act 


\title{
Modeling the Effects of Mortality on Sea Otter Populations
}

\author{
By James L. Bodkin and Brenda E. Ballachey
}

\section{Abstract}

Conservation and management of sea otters can benefit from managing the magnitude and sex composition of human related mortality, including harvesting within sustainable levels. Using age and sex-specific reproduction and survival rates from field studies, we created matrix population models representing sea otter populations with growth rates of 1.005 , 1.072 , and 1.145 , corresponding to stable, moderate, and rapid rates of change. In each modeled population, we incrementally imposed additional annual mortality over a 20 -year period and calculated average annual rates of change $(\lambda)$. Additional mortality was applied to (1) males only, (2) at a 1:1 ratio of male to female, and (3) at a 3:1 ratio of male to female. Dependent pups (age 0-0.5) were excluded from the mortality. Maintaining a stable or slightly increasing population was largely dependent on (1) the magnitude of additional mortality, (2) the underlying rate of change in the population during the period of additional mortality, and (3) the extent that females were included in the additional mortality (due to a polygnous reproductive system where one male may breed with more than one female). In stable populations, additional mortality as high as 2.4 percent was sustainable if limited to males only, but was reduced to 1.2 percent when males and females were removed at ratios of $3: 1$ or 0.5 percent at ratios of $1: 1$. In moderate growth populations, additional mortality of 9.8 percent (male-only) and 15.0 percent (3:1 male to female) maximized the sustainable mortality about 3-10 ten-fold over the stable population levels. However, if additional mortality consists of males and females at equal proportions, the sustainable rate is 7.7 percent. In rapid growth populations, maximum sustainable levels of mortality as high as 27.3 percent were achieved when the ratio of additional mortality was 3:1 male to female. Although male-only mortality maximized annual harvest in stable populations, high male biased mortality in all simulations eventually led to low proportions of males, leading to instability in projected populations over time. Our findings identify the critical need to understand underlying rates of change that can be acquired only through frequent monitoring of managed populations. Models could be improved through better understanding of the effects of density and demographic and environmental stochasticity on sea otter vital rates. Although our primary objective was to provide information useful in managing harvests of sea otters, our findings have implications for the conservation and management of sea otter populations subjected to other sources of mortality that can be quantified, such as incidental, accidental, or illegal.

\section{Introduction}

Sea otter (Enhydra lutris) populations in the North Pacific have experienced numerous large-scale fluctuations in abundance that date to prehistoric times. Periods of high and low abundance of sea otter remains in midden sites in the Aleutian archipelago suggest that harvests by indigenous peoples may have been responsible for reduced abundances that extended for centuries (Simenstad and others, 1978). Beginning in the 18th century with the large-scale commercial harvest for pelts, sea otters were systematically extirpated from most of their range from eastern Asia to northern Mexico (Lensink, 1962; Kenyon, 1969) despite an average annual harvest rate of less than 2 percent (Gorbics and Bodkin, 2001). These harvests continued until late in the 19th century when as few as 13 separate populations, mostly in Alaska and numbering in total perhaps a few hundred individuals, were all that remained. In 1911, the International Fur Seal Treaty provided sea otters with protection from further commercial harvest, signaling the process of recovery that continued unabated until late in the 20th century, when growth rates again diminished in several populations.

Remnant sea otter populations generally increased in numbers and expanded their range in Russia, Alaska, and California, with long-term annual rates of recovery ranging from about 5 to 13 percent (Bodkin and others, 1999). In the 1970s, sea otters were successfully reintroduced in Southeast Alaska, Washington, and British Columbia (Jameson and others, 1982) and annual population growth rates among translocated populations ranged from 18 to 24 percent (Bodkin and others, 1999). Current rates of change in translocated populations range from 4.7 percent in Southeast Alaska to 12.4 percent in British Columbia (Nichol and others, 2005; Esslinger and Bodkin, 2009; Laidre and others, 2009). The causes of the reduced population growth rates in Washington, Southeast Alaska, and British Columbia are largely unknown, but suitable unoccupied habitat remains in all areas. 
More recently, three instances of decline have been well documented, all resulting from elevated mortality. In at least two instances, and possibly all three, declines can be linked to human activities. Beginning in the late 1970s, the California population entered a period of decline for several years, with elevated mortality incidental to fisheries impeding recovery until management actions were implemented (Wendell and others, 1986; Estes and others, 2003). In 1989, a large oil spill in Prince William Sound, Alaska, reduced the sea otter population by as many as several thousand animals (Garrott and others, 1993), with recovery delayed for at least 12 years (Ballachey and others, 1994; Bodkin and others, 2002). In the Aleutian Archipelago, following recovery to near pre-fur trade abundances, sea otter populations once again declined precipitously late in the 20th century, resulting from elevated mortality induced by killer whale (Orcinus orca) predation (Estes and others, 1998). This decline was potentially an indirect consequence of commercial whaling in the North Pacific during the 20th century, causing a shift in killer whale diet that eventually led to predation on sea otters (Springer and others, 2003).

Harvest of sea otters by native Alaskans resumed over the past few decades under provision from the Marine Mammal Protection Act of 1972. Although the harvest is monitored by the U.S. Fish and Wildlife Service (Marine Mammals Management, Anchorage, Alaska) in terms of age and sex, the harvest is largely unregulated and the effects on population abundance have not been quantified. Additionally, an illegal take of unknown magnitude occurs over potential fisheries conflicts and for pelts throughout much of the species range (Bodkin, 2003).

Largely as a result of efforts to conserve and aid in the recovery of the species, extensive research has been conducted on sea otters over the past several decades (Riedman and Estes, 1990; Estes and Bodkin, 2002; Bodkin, 2003). Much of this research has focused on estimating vital rates (reproduction and survival) (Tinker and others, 2006). Studies have been conducted across a range of populations varying in status and trend (that is, near or below equilibrium density, and stable or increasing), providing empirical estimates of age and sex specific reproduction and survival rates suitable for constructing demographic models. Such models are amenable to exploring the effects of changing mortality or reproductive rates on population trajectories.

Samuel and Foin (1983), using demographic model simulations, provide the only published information on levels of sustainable harvest, identifying harvest rates of less than 6 percent as sustainable, assuming that the targeted population was increasing at 14 percent annually. However, as they acknowledge, their models were limited by a lack of reliable data on critical life history attributes, such as age at first reproduction, and age and sex specific reproductive and survival rates. Additional demographic data, available from studies across the range of the sea otter, provide an opportunity to develop improved demographic models for sea otters. The reduced growth rates noted in several sea otter populations and the sea otter harvest in Alaska provide an impetus for development of models examining mortality.

Our objectives in this work were to: (1) construct population models using empirically derived estimates of age and sex-specific sea otter reproduction and survival, representing a range of population growth rates, (2) evaluate the effects of imposing additional male and female mortality on population trajectories, and (3) provide information useful for developing sustainable sea otter harvest or mortality management strategies. Although these population models were developed primarily to understand potential effects of harvest by humans on sea otter populations (generally referred to as harvest mortality in this report), the simulations are independent of causes of mortality and thus broadly applicable to conservation and management of sea otters.

\section{Methods}

We obtained age and sex-specific reproductive and survival values for sea otters in Alaska from the published literature to generate three population models (table 1). In the first model, we used estimates of age and sex-specific reproduction and survival from populations that were at or near presumed equilibrium density (that is, stable). In the second, we used comparable vital rates estimated from populations that were rapidly increasing and presumed to be below equilibrium density (that is, rapid growth). When more than one estimate was available in the literature for any sex/age class, the lesser value was used for the equilibrium (stable) model, and the greater value was used for the rapidly increasing population (rapid growth) model. For the third model, vital rates from the rapid growth model were uniformly decreased for each age class to generate a population exhibiting a growth rate approximately midway between the stable and rapid growth rates (that is, moderate growth). Twenty-one age classes were used for each sex, with dependent pups aged $0-0.5$ years and juveniles $0.5-1.5$ and 1.5-2 years. In all models, age classes greater than age 2 represent 1 year each. We assumed that the sex ratio at birth was $1: 1$, females give birth to a single offspring, and the reproductive interval is 1 year. All models incorporated a polygynous reproductive system with each male potentially mating with as many as 10 females at each annual time step.

Reproductive rates in the stable population for ages 2-4 were from Prince William Sound (Bodkin and others, 1993), and ages 5-17 from Udevitz and others (1996) (reproduction was limited to these ages). Survival rates for dependent pups were from Amchitka Island (Monson and others, 2000), for ages 0.5-1.5 from Prince William Sound (Ballachey and others, 2003), and for ages 1.5-2 were the mean of ages $0.5-1.5$ and $2-3$, adjusted for 6 months. Female survival rates for ages 2-20 were from Udevitz and Ballachey (1998) and male survival rates for ages 2-20 were from Udevitz and others (1996). All vital rates from Prince William Sound were independent of 1989 oil spill effects. 
Table 1. Vital rates of sea otters used to generate population models representing stable $(\lambda=1.005)$, moderate $(\lambda=1.072)$, and rapid $(\lambda=1.145)$ rates of change.

[Reproductive rate: $\mathrm{R}$, survival rate; $\mathrm{S}$, stable and rapid growth rates were obtained from published values and the moderate rates represent the rapid growth rates reduced by 0.065 . Age class: pups $=0-0.5$ years, juveniles $=0.5-2.0$ years. Stable rates from Bodkin and others (1993), Udevitz and others (1996, 1998), Monson and others (2000), and Ballachey and others (2003). Survival rates for rapid growth reduced by 0.065 and fecundity held stable, to achieve moderate growth $(\lambda=1.072)$. Rates for rapid growth from Bodkin and others (1993), Monson and DeGange (1995), Monson and others (2000), and Ballachey and others (2003)]

\begin{tabular}{|c|c|c|c|c|c|c|c|c|c|}
\hline \multirow{3}{*}{$\begin{array}{c}\text { Age class } \\
\text { (years) }\end{array}$} & \multicolumn{9}{|c|}{ Growth rate } \\
\hline & \multicolumn{3}{|c|}{ Stable } & \multicolumn{3}{|c|}{ Moderate } & \multicolumn{3}{|c|}{ Rapid } \\
\hline & $\mathbf{R}$ & Female (S) & Male (S) & $\mathbf{R}$ & Female (S) & Male (S) & $\mathbf{R}$ & Female (S) & Male (S) \\
\hline $0-0.5$ & 0.00 & 0.47 & 0.47 & 0.00 & 0.77 & 0.77 & 0.00 & 0.83 & 0.83 \\
\hline $0.5-1.5$ & 0.00 & 0.75 & 0.53 & 0.00 & 0.84 & 0.84 & 0.00 & 0.9 & 0.9 \\
\hline $1.5-2$ & 0.00 & 0.91 & 0.85 & 0.00 & 0.9 & 0.85 & 0.00 & 0.96 & 0.91 \\
\hline $2-3$ & 0.22 & 0.92 & 0.86 & 0.35 & 0.9 & 0.85 & 0.37 & 0.96 & 0.91 \\
\hline $3-4$ & 0.64 & 0.92 & 0.86 & 0.60 & 0.9 & 0.85 & 0.64 & 0.96 & 0.91 \\
\hline $4-5$ & 0.6 & 1.00 & 0.86 & 0.68 & 0.9 & 0.85 & 0.73 & 0.96 & 0.91 \\
\hline $5-6$ & 0.73 & 1.00 & 0.86 & 0.94 & 0.9 & 0.85 & 1.00 & 0.96 & 0.91 \\
\hline $6-7$ & 0.81 & 1.00 & 0.86 & 0.88 & 0.9 & 0.85 & 0.94 & 0.96 & 0.91 \\
\hline $7-8$ & 0.85 & 1.00 & 0.86 & 0.88 & 0.9 & 0.85 & 0.94 & 0.96 & 0.91 \\
\hline $8-9$ & 0.87 & 1.00 & 0.86 & 0.88 & 0.9 & 0.85 & 0.94 & 0.96 & 0.91 \\
\hline $9-10$ & 0.89 & 0.81 & 0.86 & 0.88 & 0.9 & 0.85 & 0.94 & 0.96 & 0.91 \\
\hline $10-11$ & 0.9 & 0.81 & 0.86 & 0.88 & 0.9 & 0.85 & 0.94 & 0.96 & 0.91 \\
\hline $11-12$ & 0.9 & 0.81 & 0.86 & 0.88 & 0.9 & 0.85 & 0.94 & 0.96 & 0.91 \\
\hline $12-13$ & 0.9 & 0.81 & 0.86 & 0.88 & 0.9 & 0.85 & 0.94 & 0.96 & 0.91 \\
\hline $13-14$ & 0.91 & 0.81 & 0.86 & 0.88 & 0.9 & 0.85 & 0.94 & 0.96 & 0.91 \\
\hline $14-15$ & 0.91 & 0.81 & 0.86 & 0.88 & 0.9 & 0.85 & 0.94 & 0.96 & 0.91 \\
\hline $15-16$ & 0.91 & 0.81 & 0.86 & 0.88 & 0.9 & 0.85 & 0.94 & 0.96 & 0.91 \\
\hline $16-17$ & 0.6 & 0.00 & 0.86 & 0.88 & 0.9 & 0.85 & 0.94 & 0.96 & 0.91 \\
\hline $17-18$ & 0.00 & 0.00 & 0.00 & 0.88 & 0.9 & 0.85 & 0.94 & 0.96 & 0.91 \\
\hline $18-19$ & 0.00 & 0.00 & 0.00 & 0.88 & 0.9 & 0.85 & 0.94 & 0.96 & 0.91 \\
\hline $19-20$ & 0.00 & 0.00 & 0.00 & 0.88 & 0.00 & 0.00 & 0.94 & 0.00 & 0.00 \\
\hline
\end{tabular}

Primary differences in the vital rates we used in the three population models include reduced reproduction in young and aged females, and reduced survival in the young $(<2$ years) and aged $(>15$ years for females, $>16$ years for males) of both sexes in the stable model, compared to the rapid growth model. In comparison, the reproductive rates of prime age adults, and survival of females (ages 2-11) and most males (ages 2-17) were relatively similar across models. Reproductive rates were lowest in the stable model particularly among individuals less than 8 years old, but were similar among females aged 9-16 years in each model, averaging 0.91 (table 1). In the stable model, female reproductive senescence began at age 17 and females did not reproduce after that age. In the stable model, survival rates of young females were 0.36 (age 0.5) and 0.15 (age 1.5) less than survival rates in the rapid growth model. Survival of females in the stable model declined steadily from ages 12 to 19 , whereas female survival remained high in the moderate and rapid growth populations ( 0.90 and 0.96 , respectively; table 1$)$. Male survival rates in the first two age classes were 0.36 and 0.375 less in the stable population than in the rapid growth population, but after age 2 , male survival rates remained uniformly high until late in life (table 1). 
Each of the three population models was initialized with the vital rates as described above and with an assumed population size of 1,000 individuals with a stable age distribution. We used published estimates of variance for vital rates when available and assumed standard deviations of 0.10 of the mean when estimates were not available to generate different sets of vital rates for each simulation. Each model simulation was replicated 500 times to estimate growth rates without imposing any additional mortality. Density dependence and demographic and environmental stochasticity were not included in the simulations. The initial simulations provided average annual rates of change over 20 years for the three population models (stable, moderate, and rapid growth).

We next imposed additional incremental mortality to simulate a hypothetical harvest that varied with respect to sex ratio. We considered harvests that were (1) male only, (2) 1:1 ratio of male to female and (3) 3:1 ratio of male to female. Additional mortality was imposed as a proportion of individuals in each age class with the exception of dependent pups (ages $0-0.5$ ), which were excluded. Mortality rates were incrementally increased from values that allowed for positive growth until growth rates turned negative $(\lambda<1.00)$. For each level of additional mortality, we calculated the average annual rate of change in the population $(\lambda)$, the average annual harvest over 20 years (reported as the proportion of all non-pups in the population), the harvest number at year 20, the ending population size, and the proportion of males in the population after 20 years. The average annual harvest rate was calculated as the sum of all animals harvested in a year divided by the total number of non-pup individuals in the population for that year and averaged over the 20 years of simulations. For example, a male only harvest rate of 10 percent applied to all non-pup male age classes in a total population of 1,000 would equate to the removal of 31 males in 1 year, or 3.1 percent of the total population. This annual harvest rate was then averaged over 20 years and then divided by the proportion of non-pups in the population in year 20. For example, assuming an average annual harvest of 3.1 percent and non-pups account for 77 percent of this total population, this would equate to a corrected average annual harvest rate of 4.03 percent (3.1/0.77). To calculate maximum sustainable harvest levels for each population, we required that the mean and final harvest number were approximately equal, the population size in year $20 \geq 1000$, and the average annual rate of change $(\lambda)$ was $>1.00$. To evaluate the effect of the assumed degree of polygyny (1:10 ratio of male to female), we altered the degree of polygyny to $1: 2,1: 4,1: 6$, and $1: 20$ ratios of male to female in our maximum sustainable harvest models (where $\lambda \geq 1.0$ and with polygyny initially set at $1: 10$ ratio of male to female). The software program RAMAS ${ }^{\circledR}$ Metapop 5.0.3 (Akçakaya, 2005) was used to perform all model simulations.

\section{Results}

The stable age/sex distribution generated from each population prior to any additional mortality resulted in a sex ratio of 0.40:0.60 male to female in the stable population, and 0.46:0.54 male to female in the moderate and rapid growth populations. This resulted largely from lower male survival in juvenile age classes in the stable population compared to the moderate and rapid growth populations. The final age distribution included 0.26 dependent pups (ages $0-0.5$ ) in the stable population, and 0.21 in the moderate and rapid growth populations.

\section{Population Growth Rates}

The vital rates used in these models, estimated from sea otter populations at or near equilibrium density (stable) and from rapid growth populations, yielded average annual rates of change of 1.005 and 1.145, respectively (fig. 1). A third population with intermediate growth was achieved by multiplying the rapid growth vital rates by 0.935 in each age class, resulting in an average annual rate of change of 1.072, considered to be moderate growth (fig. 1).

\section{Additional Mortality}

The effects of additional mortality on growth rates in the modeled populations were largely dependent on three factors: (1) the magnitude of additional mortality, (2) the rate of population change prior to the additional mortality, and (3) the sex composition of the additional mortality (fig. 2). In a stable population, additional annual mortality of about 0.5 percent that included females at a 1:1 ratio or of 1.2 percent at a male to female ratio of 3:1 resulted in population decline $(\lambda<1.00)$ (fig. $2 A$ ). If additional mortality is constrained to males only, harvest rates of more than 2.4 percent resulted in population decline. As additional annual mortality of only males exceeded this rate, $\lambda$ decreased rapidly, largely as a result of reduced proportions of males in the population. After 20 years of a male harvest of 2.4 percent annually, the proportion of males in the population equaled 34 percent, compared to 40 percent without a harvest. The annual average rate of change $(\lambda)$ declined linearly with mortality rates when both males and females were included in the harvest, independent of the underlying growth rate in the population (fig. 2A).

In a population exhibiting moderate growth (fig. $2 B$ ), additional annual male mortality of more than 9.8 percent resulted in $\lambda<1.00$. As mortality of males only exceeded this rate, $\lambda$ decreased largely as a result of reduced proportions 


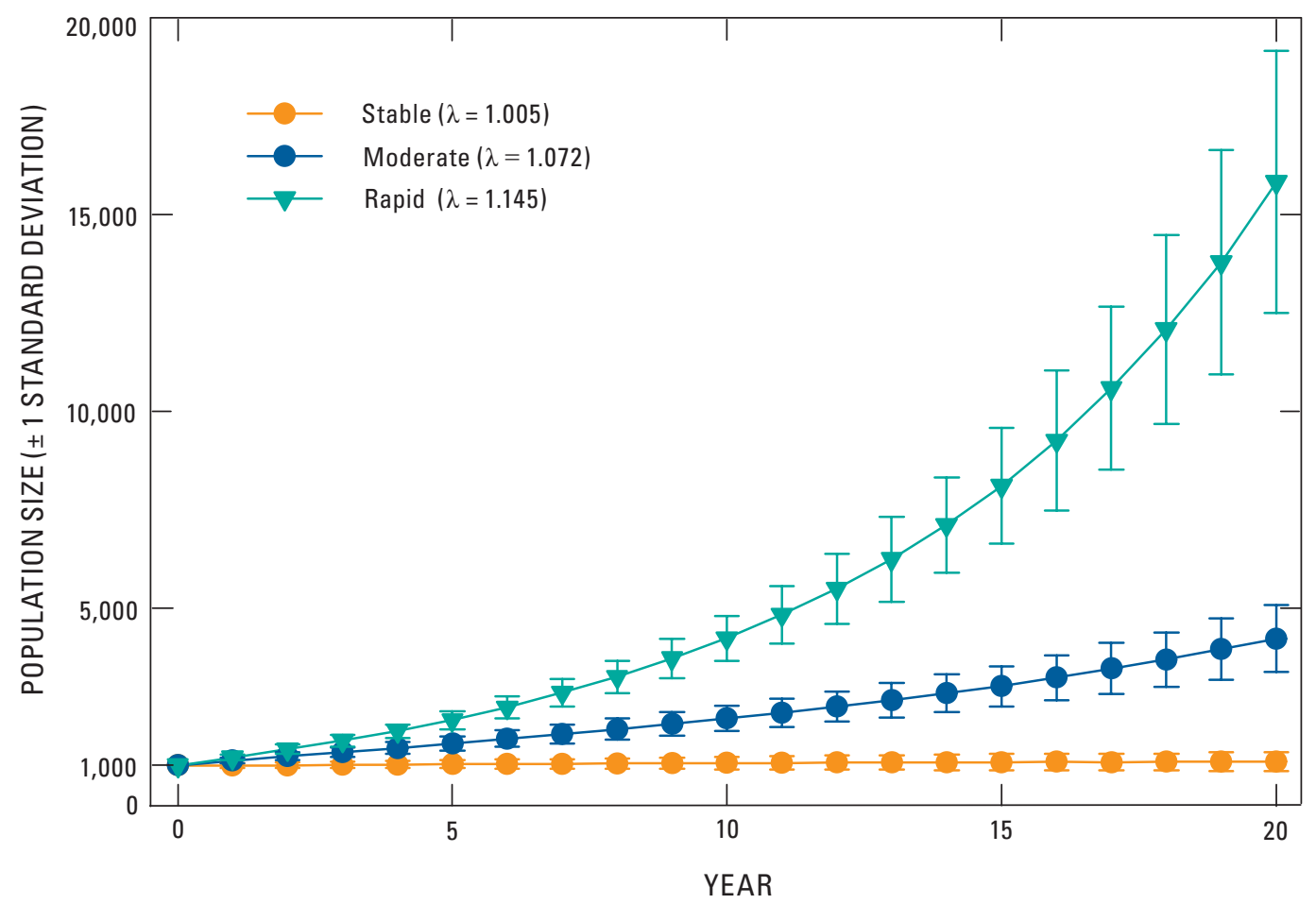

Figure 1. Population trajectories over 20 years for sea otter populations exhibiting stable, moderate, and rapid rates of change using empirical estimates of age and sex specific reproduction and survival. Error bars represent +1 standard deviation from the mean.

of males in the population, with the proportion of males after 20 years equaling 27 percent compared to 46 percent without a harvest. If females at a 1:1 ratio were included in the additional mortality, $\lambda$ decreased to $\leq 1.00$ when average annual mortality exceeded 7.7 percent. When males and females were harvested at a 3:1 ratio, additional mortality resulted in $\lambda \leq 1.00$ at a mortality rate of 15.0 percent (fig. $2 B$ ).

In a population exhibiting rapid growth (fig. $2 \mathrm{C}$ ), additional male only mortality of more than about 8.5 percent annually resulted in low proportions of males in the population. Although $\lambda$ remained positive (1.04) at an average annual male mortality of 8.5 percent, the proportion of males after 20 years equaled 14 percent compared to 46 percent without a harvest. Further increases in male only annual mortality led to both negative $\lambda$ values and reduced average annual harvests (fig. 2C). If females at a 1:1 ratio were included in the additional mortality, $\lambda$ was $\leq 1.00$ when average annual mortality exceeded 16.2 percent. When males and females were included at a 3:1 ratio, additional mortality resulted in $\lambda \leq 1.00$ at a mortality rate of about 27 percent (fig. 2C).

\section{Maximum Sustainable Harvests}

Maximum sustainable harvests were dependent on the underlying rate of change in the population and the sex composition of the harvest (fig. 3), and ranged from about 0.5 to 27 percent. For stable populations near equilibrium density, male only harvests allowed a maximum sustainable harvest of 18 individuals per year out of a population of 1,000 individuals. This resulted in an average annual harvest rate of 2.4 percent of the non-pup population and a final abundance that exceeded initial abundance. Although an average annual harvest rate of about 4 percent also resulted in a positive $\lambda$, the population abundance in year 20 was less than the initial abundance (fig. 2A). Inclusion of females in the harvest reduced the maximum average annual harvest rates to 1.2 and 0.5 percent at male to female ratios of $3: 1$ and $1: 1$, with maximum average sustainable annual harvests of nine and four individuals, respectively. Average annual rates of change over the 20-year period at maximum sustainable harvest rates ranged from 1.002 for male only harvests to 1.001 when females were included. At all maximum sustainable mortality rates, the proportion of males in the population after 20 years exceeded 0.34 . 

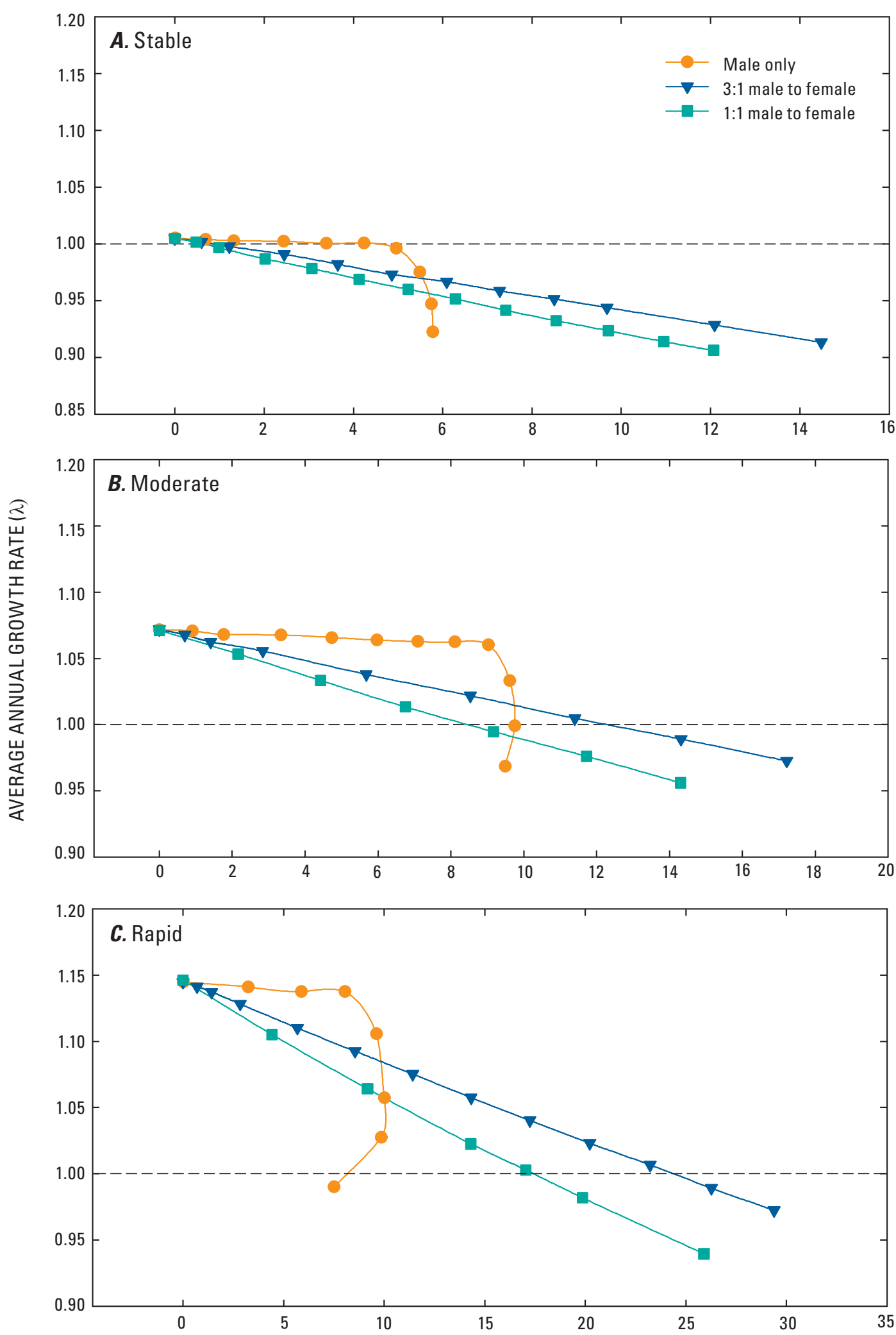

AVERAGE ANNUAL HARVEST, AS PERCENTAGE OF NON-PUPS IN POPULATION

Figure 2. Effects of additional sex and age specific mortality (removals) on rates of change in sea otter populations that are stable $(\lambda=1.005)$, increasing moderately $(\lambda=1.072)$, and increasing rapidly $(\lambda=1.145)$. Additional mortality occurs annually over 20 years as a proportion of individuals in each age/sex class except dependent pups. Additional mortality was applied to males only, and at male to female ratios of 3:1 and 1:1. As harvest levels rise sufficient to reduce $\lambda$ to 1.0 , declines in average annual harvest over time are particularly evident in graphs $B$ and $C$. Note differences in scales on $\mathrm{x}$ axis. 


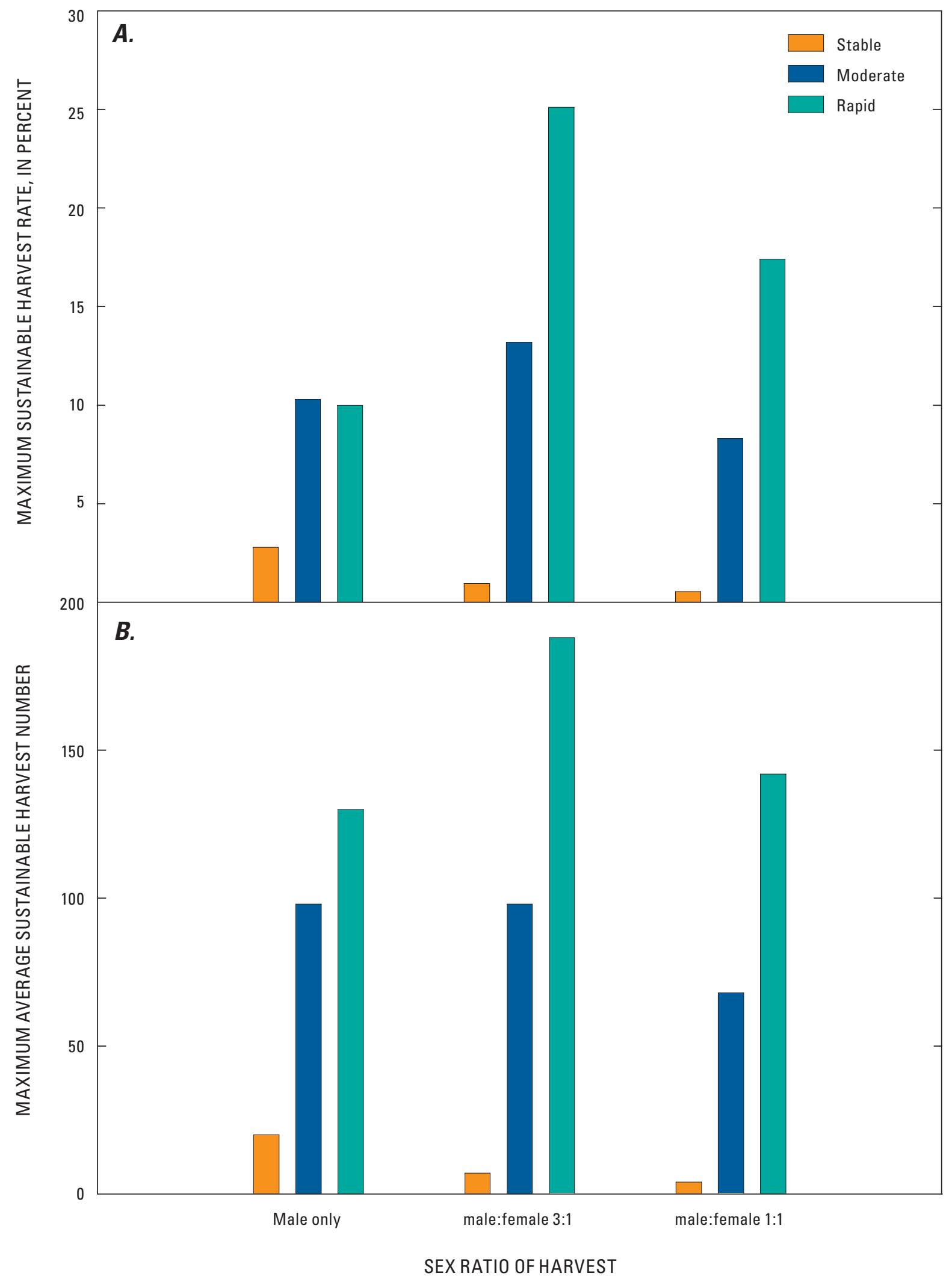

Figure 3. Maximum annual sustainable rates of harvest for sea otter populations experiencing stable, moderate, and rapid growth $(A)$, and maximum sustainable average annual harvest number $(B)$ for male only, and male to female ratios of $3: 1$ and 1:1. Initial population size is 1000 , and results were constrained to model outputs where $\lambda>1.00$ and final harvest number equaled the average annual harvest. 
In a population of 1,000 exhibiting moderate growth, a male only harvest of 100 individuals per year was sustainable (fig. 3) with an average annual rate of change of 1.01; however, the proportion of males in the population after 20 years was 0.27 . With a harvest ratio of $3: 1$ male to female, a sustainable harvest rate was 15 percent, resulting in an average annual harvest of 107 individuals with a final proportion of males of 0.34 . If the harvest ratio was $1: 1$, the maximum sustainable annual harvest was 67 individuals, with a final male proportion of 0.46 .

In these simulations, maximum sustainable annual harvest rates and average harvest number were greatest in populations exhibiting rapid growth (fig. 3). In a population of 1,000 exhibiting rapid growth, an average annual male only harvest of up to 8 percent did not reduce $\lambda$ and allowed an average annual harvest of 283 individuals (fig. 2C).

However, at an annual harvest rate of 8.5 percent, removal of 120 individuals was sustainable (fig. 3) with $\lambda=1.04$ but, the proportion of males in the population after 20 years was 0.14 . When females were included at a ratio of 3:1 male to female, a maximum average sustainable harvest rate of 27 percent was possible, with an average annual harvest of 191 individuals and a 20 -year average annual growth rate of 1.00 . For this harvest simulation, the proportion of males after 20 years had declined to 0.28 . At a $1: 1 \mathrm{sex}$ ratio, the maximum sustainable annual harvest rate was 16.2 percent with a maximum average annual sustainable harvest of 144 individuals, and a final male proportion of 0.46 .

\section{Effects of Rates of Polygyny}

Results presented above (igs. 1- ) assume a mating ratio of 1:10 male to female. As we decreased the degree of polygyny from the assumed value to a minimum of 1:2 male to female (presumably much too conservative), we observed negative rates of change in seven of the nine maximum sustainable harvest simulations (all simulations except moderate and rapid growth at 1:1 harvest ratios). At a polygyny ratio of 1:4 male to female, growth stabilized with $\lambda \geq 1.00$ in the stable population under all maximum harvest simulations, but populations declined in mixed sex harvests in moderate and rapid growth models. At polygyny rates of 1:6 male to female, we observed declines in the moderate growth population with male only harvest and in the rapid growth population with a 3:1 harvest. We detected no diminishment in $\lambda$ as polygyny increased to the 1:20 ratio of male to female but did detect increased rates of change in the moderate and rapid growth populations with the higher levels of polygyny.

\section{Discussion}

Managers of wildlife resources have a responsibility for conserving and sustaining resources, and pursue various strategies to meet management objectives, including habitat conservation and manipulation (Poole and Mowat, 2005), management of movements (Beier and Noss, 1998), and reproduction (DeNicola and others, 1997). Most commonly, however, it is mortality, often human related, that provides the means for active management of populations (Strickland and others, 1996). Population management can include various objectives, including increasing or decreasing population abundance, or maximizing rates of harvest by humans or productivity in the population (Caughley, 1977). One widely applied population management tool is the demographic model based on life history attributes in a Leslie matrix (Caughley, 1977). Although acquisition of empirically derived age and sex-specific reproduction and survival rates required by such models can be time and labor consuming, particularly for long-lived species, application of those values in demographic models to guide conservation and manage populations is relatively straight-forward (Johnson, 1996).

\section{Assumptions}

We created three sea otter demographic models using age and sex-specific reproduction and survival rates obtained from field studies of populations that simulated stable, moderate, and rapid rates of population growth. We then applied additional incremental mortality to each simulation to evaluate effects on population growth rates. Although model outcomes illustrate clear effects of additional mortality, particularly as maximum sustainable levels are approached and exceeded, it is important to recognize and evaluate the assumptions inherent in this approach.

Perhaps most importantly, we assumed that the vital rates used in each model simulation remained constant and within the bounds estimated from field studies, and that annual rates of change in the population prior to additional mortality are constant. However, this certainly is not always true, based on long-term studies of wildlife around the globe (Gaillard and others, 1998; Wisdom and others, 2000), including sea otters specifically (Tinker and others, 2006). Rather, the underlying vital rates, particularly survival, tend to vary on temporal and spatial scales that are specific to individual species' life histories, and often reflect environmental and ecological conditions. Thus, although the model outcomes we present here can be useful for guiding mortality management of sea otters, it is essential that managers recognize the need to incorporate accurate rates of change in the application 
of the types of models we describe. Permitting the high rates of additional mortality sustainable in a rapid growth population, if the rate of change declines, could clearly result in a declining population through unsustainable additional mortality. For example, prior to 1994, the sea otter population in Southeast Alaska was increasing at about 18 percent per year (Bodkin and others, 1999). A survey conducted in 2002-03 showed that the annual growth rate since 1994 was reduced to 5 percent or less (Esslinger and Bodkin, 2009). If mortality had been managed on the higher growth rate, the sea otter population in Southeast Alaska may have declined in abundance as a consequence of excessive harvest during the long interval between surveys.

We also assumed that additional mortality (that is, harvests or incidental mortality) rates are known, accurate, and applied to each age and sex as prescribed. Our models also assume that females with dependent pups are not included in the additional mortality. Again, to some extent, these assumptions may not be true. Mortality can be undetected or unreported and novel sources of mortality can emerge to supplement known sources of mortality that are being managed. At least in the case of sea otters, it seems likely that reported mortality (for example, harvests or incidental fisheries take) will underestimate actual mortality to the extent that such sources remain undetected or under-reported. Thus, it would seem prudent to incorporate some level of undetected managed mortality into models used for management.

Frequent estimates of trend in rates of population change also would serve to evaluate the potential effects of undetected or underestimated mortality.

In male only mortality models, we detected a strong adverse effect on population trajectory beyond maximum sustainable rates from about 2 to 9 percent (fig. 2). We assumed a ratio of 1 male to 10 females to represent the level of polygyny in each of our models. The rapid declines likely arise from diminishing proportions of males in the population and the assumed polygyny we imposed in the models. Reducing polygyny to $\leq 1: 4$ (male to female) resulted in declining populations under maximum sustainable male biased mortality models in the moderate and rapid growth populations, but not in the stable population. Assuming a higher degree of polygyny (for example, 1:20 ratio of male to female) can increase population sizes under male only harvests but also can result in even lower proportions of males after 20 years. These results suggest a conservative approach (that is, 1:10 ratio of male to female or less) is warranted until additional research provides empirical data on the degree of polygyny in this species. Because of the effects of sex-specific mortality on rates of population change, the sex composition of managed mortality should be determined and incorporated into future models. Further, such models could incorporate the appropriate functional response to changing levels of polygyny, particularly if sex-biased mortality leads to highly skewed sex ratios.

We did not incorporate catastrophes, environmental or demographic stochasticity, or density dependence into the mortality simulations. Our intent in this work is to produce examples of an approach to improve the management of sea otter mortality. It is our premise that incorporation of these types of processes would do little to enhance the demonstration of demographic models as a management tool. Additionally, we have little empirical data from which to estimate and incorporate such processes into the models. We suggest that as data from field studies are acquired through additional research, that those processes and sources of uncertainty be explicitly incorporated into future models as feasible. Examples of such processes might include mortality associated with catastrophic pollution events, such as the 1989 Exxon Valdez oil spill (Ballachey and others, 1994), or density-dependent reductions in population size and growth rate (Bodkin and others, 2000). However, managing mortality for an annual average rate of change approximating 1.0, as in our simulations, would tend to moderate any densitydependent effects on vital rates.

\section{Spatial Considerations}

The geographical scale at which sea otter populations are managed remains an important, although largely unexplored issue. As noted by Gorbics and Bodkin (2001), the annual harvest rate during the commercial fur trade of the 18th and 19th centuries averaged only about 1.5 percent per year of the global sea otter population. Over that time, range-wide reductions and extirpations occurred not simply because of excessive harvest, but because the harvest was not allocated proportional to the abundance and distribution of sea otters. This resulted in the serial depletion of otters beginning in the western Pacific that systematically expanded eastward across the Aleutian Archipelago and southward along North America, as harvested populations became either reduced to unprofitable densities or became locally extinct. The process of serial depletion was facilitated by the relatively sedentary nature of sea otters. Annual home range sizes of adult sea otters are relatively small, with male territories ranging from 4 to $11 \mathrm{~km}^{2}$ and adult female home ranges from a few to $24 \mathrm{~km}^{2}$ (Garshelis and Garshelis, 1984; Ralls and others, 1988; Jameson, 1989). When additional mortality is spatially concentrated in areas equal to or smaller than the cumulative home range of the managed population, local depletion, potentially leading to serial depletion, may occur. Therefore, it is essential to consider the spatial scales at which sea otter mortality is managed. 
At least two general approaches to the issue of spatial distribution of mortality are evident. One approach is to assure that mortality is spatially distributed proportional to sea otter abundance. In this case, the size of the area managed is of relatively little consequence provided that it is large enough to support a self sustaining population (that is, adequate numbers of individuals in each age and sex class). A second approach to managing mortality would be to identify subunits within geographic areas that display demographically distinct population trends and manage mortality according to those differences in rates of population change (Tinker and others, 2008). Models, such as those we created, can incorporate meta-population analysis, but will require new data on movement and dispersal rates among subpopulations, particularly among juvenile age classes. In either case, mortality management will be facilitated by relatively frequent surveys of distribution and abundance at spatial scales consistent with managed sources of mortality.

\section{Summary}

Sea otter populations are subjected to a variety of human related sources of mortality that are amenable to management. We developed demographic models that represent stable, moderate, and rapid rates of change in sea otter populations and applied additional age and sex-specific mortality in each model. Our methods and results identify important ways in which sea otter conservation and management can be improved through modeling. In addition to the magnitude of the additional mortality, two other factors were important in determining the effect of additional mortality on the population. One was the underlying rate of change in the population, that is, populations that were increasing could sustain higher mortality than stable populations. The second was the sex ratio of the additional mortality, as high levels of male only mortality eventually resulted in low proportions of males in the population and instability in population projections. Our findings illustrate the essential need to obtain frequent information on the rates of change in managed populations, and the magnitude and sex composition of additional mortality. It also will be important to consider the spatial scales at which additional mortality is occurring to avoid the potential for serial depletion across populations. Although the models we describe may be most suitable for harvest management, other sources of quantifiable mortality, such as incidental, accidental, or illegal, can readily be incorporated into this modeling approach.

\section{Acknowledgments}

This work was supported by the U.S. Geological Survey, Alaska Science Center. Doug Burn, Brian Hatfield, Kim Kloecker, Karen Oakley, Joel Schmutz, Tim Tinker, and Mark Udevitz contributed valuable suggestions to improve the manuscript.

\section{References Cited}

Akçakaya, H.R., 2005, RAMAS Metapop: Viability analysis for stage-structured metapopulations (v. 5): Applied Biomathematics, Setauket, NY.

Ballachey, B.E., Bodkin, J.L., and DeGange, A.R., 1994, An overview of sea otter studies, in Loughlin, T.R., ed., Marine Mammals and the Exxon Valdez: San Diego, CA., Academic Press, p. 47-59.

Ballachey, B.E., Bodkin, J.L., Howlin, S., Doroff, A.M., and Rebar, A.H., 2003, Correlates to survival of juvenile sea otters in Prince William Sound, Alaska: Canadian Journal of Zoology, v. 81, p. 1494-1510.

Beier, P., and Noss, R.F., 1998, Do habitat corridors provide connectivity?: Conservation Biology, v. 12, p. 1241-1252.

Bodkin, J.L., 2003, Sea Otter, Enhydra lutris, in Feldham, G.A., Thompson, B.C. and Chapman, J.A., eds., Wild Mammals of North America, 2nd ed.: Baltimore, Johns Hopkins University Press, p. 735-743.

Bodkin, J.L., Ballachey, B.E., Cronin, M.A., and Scribner, K.T., 1999, Population demographics and genetic diversity in remnant and re-established populations of sea otters: Conservation Biology, v. 13, p. 1278-1385.

Bodkin, J.L., Ballachey, B.E., Dean, T.A., Fukuyama, A.K., Jewett, S.C., McDonald, L.M., Monson, D.H., O’Clair, C.E., and VanBlaricom, G.R., 2002, Sea otter population status and the process of recovery from the Exxon Valdez oil spill: Marine Ecology Progress Series, v. 241, p. 237-253.

Bodkin, J.L., Burdin, A.M., and Ryzanov, D.A., 2000, Age and sex specific mortality and population structure in sea otters: Marine Mammal Science, v. 16, p. 201-219.

Bodkin, J.L., Mulcahy, D., and Lensink, C.J., 1993, Age specific reproduction in the sea otter (Enhydra lutris); an analysis of reproductive tracts: Canadian Journal of Zoology, v. 71, p. 1811-1815. 
Caughley, G., 1977, Analysis of vertebrate populations: New York, John Wiley \& Sons, 234 p.

DeNicola, A.J., Kesler, D.J., and Swihart, R.K., 1997, Remotely delivered prostaglandin $\mathrm{F}_{2 \alpha}$ implants terminate pregnancy in white tailed deer: Journal of Wildlife Management, v. 25, p. 527-531.

Esslinger, G.E., and Bodkin, J.L., 2009, Status and trends of sea otter populations in Southeast Alaska, 1969-2003: U.S. Geological Survey Scientific Investigations Report 2009-5045, $18 \mathrm{p}$

Estes, J.A., and Bodkin, J.L., 2002, Marine Otters, in Perrin, W.F., Wursig, B., and Thewissen, J.G.M., eds., Encyclopedia of Marine Mammals: Academic Press, p. 843-858.

Estes, J.A., Hatfield, B.B., Ralls, K., and Ames, J., 2003, Causes of mortality in California sea otters during periods of population growth and decline: Marine Mammal Science, v. 19, p. $198-216$.

Estes, J.A., Tinker, M.T., Williams, T.M., and Doak, D.F., 1998, Killer whale predation on sea otters linking coastal with oceanic ecosystems: Science, v. 282, p. 473-476.

Gaillard, J.M., Festa-Bianchet, M., and Yoccoz, N.G., 1998, Population dynamics of large herbivores:variable recruitment with constant adult survival: Trends in Ecology \& Evolution, v. 13, p. 58-63.

Garrott, R., Eberhardt, L.L., and Burn, D.M., 1993, Mortality of sea otters in Prince William Sound following the Exxon Valdez oil spill: Marine Mammal Science, v. 9, p. 343-359.

Garshelis, D.L., and Garshelis, J.A., 1984, Movements and management of sea otters in Alaska: Journal of Wildlife Management, v. 48, p. 665-677.

Gorbics, C., and Bodkin, J.L., 2001, Stock identity of sea otters in Alaska: Marine Mammal Science, v. 17, p. 632-647.

Jameson, R.J., 1989, Movements, home ranges, and territories of male sea otters off central California. Marine Mammal Science, v. 5, p. 159-172.

Jameson, R.J., Kenyon, K.W., Johnson, A.M., and Wight, H.M., 1982, History and status of translocated sea otter populations in North America: Wildlife Society Bulletin, v. 10 , p. $100-107$.

Johnson, D.H., 1996, Population management, in Bookhout, T.A., ed., Research and management techniques for wildlife and habitat, (5th ed., rev.): Bethesda, MD, The Wildlife Society, $740 \mathrm{p}$.
Kenyon, K.W., 1969, The sea otter in the eastern Pacific Ocean: North American Fauna 68, 352 p.

Laidre, K.L., Jameson, R.J., Gurarie, E., Jefferies, S.J., and Allen, H., 2009, Spatial habitat use patterns of sea otters in coastal Washington: Journal of Mammalogy, v. 90, p. 906-917.

Lensink, C.J., 1962, The history and status of sea otters in Alaska: Indiana, Purdue University, Ph.D. dissertation, $165 \mathrm{p}$.

Monson, D.H., and DeGange, A.R., 1995, Reproduction, preweaning survival, and survival of adult sea otters at Kodiak Island, Alaska: Canadian Journal of Zoology, v. 73, p. 1161-1169.

Monson, D.H., Estes, J.A., Bodkin, J.L., and Siniff, D.B., 2000, Life history plasticity and population regulation in sea otters: Oikos, v. 90, no. 3, p. 457-468.

Nichol, L.K., Watson, J.C., Ellis, G.M., and Ford, J.K.B., 2005, An assessment of abundance and growth of the sea otter population (Enhydra lutris) in British Columbia: Canada Department of Fisheries and Oceans, Canadian Science Advisory Secretariat Report 2005/094, 22 p.

Poole, K., and Mowat, G., 2005, Winter habitat relationships of deer and elk in the temperate interior mountains of British Columbia: Wildlife Society Bulletin, v. 33, no. 4, p. $1288-1302$.

Ralls, K., Eagle T., and Siniff, D.B., 1988, Movement patterns and spatial use of California sea otters, in Siniff, D.B., and Ralls, K., eds., Final Report on Contract No. 14-12-0013003, Population status of California sea otters: Minerals Management Service, Los Angeles, CA, p. 33-63.

Riedman, M.L., and Estes, J.A., 1990, The sea otter (Enhydra lutris): Behavior, ecology and natural history: U.S. Fish and Wildlife Service Biological Report 90, no. 14.

Samuel, M.D., and Foin, T.C., 1983, Exploiting sea otter populations: A simulation analysis: Ecological Modelling, v. 20, p. 297-309.

Simenstad, C.A., Estes, J.A., and Kenyon, K.W., 1978, Aleuts, sea otters, and alternate stable-state communities: Science, v. 200 , no. 4340 , p. $403-411$.

Springer, A., Estes, J.A., vanVliet, G., Williams, T.M., Doak, D., Danner, E., Forney, K., and Pfister, B., 2003, Sequential megafaunal collapse in the North Pacific Ocean: An ongoing legacy of industrial whaling?: Proceedings of the National Academy of Sciences, v. 100, p. 12223-12228. 
Strickland, M.D., Harju, H.J., McCaffery, K.R., Miller, H.W., Smith, L.M., and Stoll, R.J., 1996, Harvest Management, in Bookhout, T.A., ed., Research and Management Techniques for Wildlife and Habitat (5th ed., rev.): Bethesda, MD, The Wildlife Society, p. 445-473.

Tinker, M.T., Doak, D.F., Estes, J.A., Hatfield, B.B., Staedler, M.M., and Bodkin, J.L., 2006, Incorporating diverse data and realistic complexity into demographic estimation procedures: A case study using the California sea otter, Enhydra lutris nereis: Ecological Applications, v. 16, p. 2293-2312.

Tinker, M.T., Doak, D.F., and Estes, J.A., 2008, Using demography and movement behavior to predict range expansion of the southern sea otter: Ecological Applications, v. 18, p. 1781-1794.

Udevitz, M.S., and Ballachey, B.E., 1998, Estimating survival rates with age-structure data: Journal of Wildlife Management, v. 62, p. 779-792.
Udevitz, M.S., Ballachey, B.E., and Bruden, D.L., 1996, A population model for sea otters in Western Prince William Sound: Exxon Valdez Oil Spill State/Federal Restoration Project Final Report (Restoration Study 93043-3), Anchorage, AK, Exxon Valdez Oil Spill Trustee Council.

Wendell, F.E., Hardy, R.A., and Ames, J.A., 1986, An assessment of the accidental take of sea otters, Enhydra lutris, in gill and trammel nets: California Department of Fish and Game, Marine Resources Technical Report 54, $31 \mathrm{p}$.

Wisdom, J.J., Mills, L.S., and Doak, D.F., 2000, Life stage simulation analysis: Estimating vital-rate effects on population growth for conservation: Ecology, v. 81, p. 628-641. 
Publishing support provided by the U.S. Geological Survey

Publishing Network, Tacoma Publishing Service Center

For more information concerning the research in this report, contact the Director, Alaska Science Center

U.S. Geological Survey

4210 University Drive

Anchorage, Alaska 99508

http://alaska.usgs.gov 


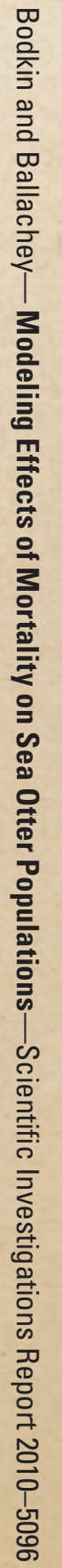

